\title{
Effect of Recycled Aggregates on the Energy Dissipation Capacity of RC Beam subjected to Reverse Cyclic Flexural Loading
}

\author{
Muhammad Rizwan Riaz ${ }^{1 \mathrm{a}}$, Rashid Hameed ${ }^{1 \mathrm{~b}}$, Usman Akmal ${ }^{1 \mathrm{c}}$, Asad Ali Gillani ${ }^{1 \mathrm{~d}}$, \\ Muhammad Ilyas ${ }^{2}$
}

RECEIVED ON 15.05.2019, ACCEPTED ON 03.03.2020

\begin{abstract}
The energy dissipation capacity of concrete is an important aspect for a Reinforced Concrete (RC) structure to be seismically resistant. Various types of concrete incorporating sustainable materials are being developed these days such as recycled aggregate concrete. Determination of energy dissipation capacity of such new types of concrete is of great importance for their application in RC structures which are to be constructed in seismically active areas. In this regard, the experimental study presented in this contribution investigated the energy dissipation capacity of RC beams constructed using recycled aggregate concrete and subjected to three different deflection amplitude levels of reverse cyclic flexural loading. For this purpose, a total of $20 \mathrm{RC}$ beams of cross section $75 \times 150 \mathrm{~mm}$ and length of $1350 \mathrm{~mm}$ were cast using five different concrete compositions and tested. Among five different concrete compositions, one was control concrete containing $100 \%$ natural aggregates while the remaining four compositions were of recycled aggregate concrete containing natural and recycled aggregates. Four replacement levels $(25 \%, 50 \%, 75 \%$, and $100 \%)$ of natural aggregates with recycled aggregates were examined. Results indicated that the amplitude level of imposed deflection is an important factor which influenced the value of energy dissipated by RC beams. Further, results showed that RC beam constructed using recycled aggregate concrete containing $25 \%$ recycled aggregates exhibited energy dissipation capacity similar to or even better than that of control RC beam containing $100 \%$ natural aggregates.
\end{abstract}

Keywords: RC Beam, Recycled Aggregates, Reverse Cyclic Loading, Cracking; Energy Dissipation

\section{INTRODUCTION}

I many countries, rapid development, modernization, and industrialization in recent years have generated large amounts of debris in the form of Construction and Demolition (C\&D) waste. A major portion of C\&D waste is generated from demolished structures that were previously constructed using normal strength concrete and are recently being replaced by more efficient structures with smart structural members and high strength materials because of the increasing need for space and aesthetics. Other sources of C\&D waste include demolition of structures caused by expired design life or inadequate design; demolished structures which are severely damaged by natural disasters such as earthquakes, floods, and windstorms; damaged structures in events of war; tested concrete samples in testing-laboratories to ensure the quality of concrete for any specific project; defected members in pre-cast concrete industries and surplus concrete from readymix concrete plants. Deciding what to make of this waste is a major challenge and its recycling has become essentially important to ensure the

\footnotetext{
${ }^{1}$ Department of Civil Engineering, University of Engineering and Technology, Lahore, Pakistan. Email: ${ }^{a}$ rizwan.riaz@ uet.edu.pk (Corresponding Author), brashidmughal@uet.edu.pk, ${ }^{c}$ usman.akmal@uet.edu.pk, dasadgillani@uet.edu.pk,

${ }^{2}$ Department of Civil Engineering, Lahore Leads University, Lahore, Pakistan. Email: ilyas@ucest.edu.pk This is an open access article published by Mehran University of Engineering and Technology, Jamshoro under CC BY 4.0 International License.
} 
preservation of the environment, sustainable development and effective utilization of available resources. These days this C\&D waste is being converted into aggregates and used in concrete which is termed as "Recycled Aggregate Concrete (RAC)".

Research conducted on the characterization of RAC in the recent past [1-10] has in general revealed lesser compressive and bending strengths, lower modulus of elasticity and lesser durability as compared to Natural Aggregate Concrete (NAC). The major reason for the lesser durability of RAC is higher permeability and more water requirement of recycled aggregates. Currently, RAC is being used as non-structural concrete in the construction industry; however, before the RAC can be used in the main load-carrying structural members, significant research needs to be carried out to check its structural performance, safety, and reliability under different loading and exposure conditions.

Pakistan, being under the influence of three tectonic plates, has many areas susceptible to seismic activity. A major aspect of the structural performance of concrete in seismically active regions is its ability to adequately dissipate the energy when subjected to cyclic loading. Such ability of concrete is of great importance in situations such as concrete floors subjected to vibration caused by the moving crowd, concrete structures subjected to the earthquake as well as vibration in concrete elements due to mechanical loading. Therefore, the energy dissipation capacity of $\mathrm{RAC}$ is an important aspect for checking its structural performance and suggesting its usage in structural elements subjected to cyclic flexural loading.

$\mathrm{Hu}$ et al. [11] studied the stress-strain response of RAC under compressive cyclic loading and found that NAC and RAC demonstrated similar failure characteristics under monotonic and cyclic loadings. Peng et al. [12] investigated fatigue performance of RAC and revealed that fatigue life, residual strength, and stiffness of RAC decreased with an increased replacement level of RA. While studying the flexural bond behavior of reinforced RAC, Dong et al. [13] found a similar mode of reinforcement failure in RAC and NAC and further revealed a decrease in bond strength with an increase in RA content. Kim et al.
[14] investigated the behavior of RAC confined by spiral reinforcement. The study parameters included replacement level of NA with RA and steel ratio and yield strength of spiral reinforcement. They found that cylindrical specimens constructed using RAC and confined by spiral reinforcement exhibited structural performance similar to that of NAC specimens. Mohamad et al. [15] studied the structural performance of RA in the concrete sandwich precast slab by carrying out flexural load tests and revealed a decrease in flexural strength of slab panels with an increase in contents of RA. The findings of research studies [16-18] carried out in the recent past to investigate the mechanical performance of $\mathrm{RC}$ structural members constructed using RAC and subjected to cyclic or seismic loadings have revealed that although the energy dissipation capacity and ductility is degraded by replacing the NA with RA; but still RAC fulfills the related requirements of earthquake resistance designing. In the authors' point of view, still much research work needs to be carried out in this area to draw some final conclusions and to formulate final recommendations for the use of RAC in structures situated in seismically active regions.

The research reported herein is to investigate the behavior of RC beams made using RAC and subjected to reverse cyclic bending. The main objective of this research study was to experimentally determine the effect of replacement of NA by RA obtained from precast concrete industry on energy dissipated by $\mathrm{RC}$ beams subjected to reverse-cyclic bending. Since many areas in Pakistan are susceptible to earthquake loading; the outcome of such experimental studies could be important and useful to devise recommendations regarding the application of RAC in real RC structures in seismically active regions.

\section{EXPERIMENTAL PROGRAM}

\subsection{Materials}

\subsubsection{Cement and Natural Aggregates (NA)}

ASTM Type I Portland cement, locally available river sand as fine aggregates and locally available crushed stone as natural coarse aggregates (refer to Fig.1) were used for this study to prepare concrete mixes. The 
properties of both fine and natural coarse aggregates are given in Table 1 and Table 2, respectively.

\subsubsection{Recycled Aggregates (RA)}

Recycled aggregates for this study were retrieved from waste concrete from the precast concrete industry. Damaged pre-cast beams (damaged during handling and testing) and tested concrete samples (cubes and cylinders) having a minimum compressive strength of $35 \mathrm{MPa}$ were used to produce RA of maximum particle size as $12 \mathrm{~mm}$ (refer to Fig.2). The properties of RA are given in Table 2 .

Table 1: Properties of fine aggregates (Sand)

\begin{tabular}{|l|c|}
\hline \multicolumn{1}{|c|}{ Property } & Value \\
\hline Max. Aggregate Size (mm) & 4 \\
\hline Water Absorption (\%) & 0.9 \\
\hline Moisture Content (\%) & 0.4 \\
\hline Specific Gravity & 2.61 \\
\hline Bulk Density (Rodded) $\left(\mathrm{kg} / \mathrm{m}^{3}\right)$ & 1641 \\
\hline Fineness Modulus & 2.4 \\
\hline
\end{tabular}

Table 2: Properties of NA and RA

\begin{tabular}{|l|c|c|}
\hline \multicolumn{1}{|c|}{ Property } & NA & RA \\
\hline Size Range (mm) & 4 to12 & 4 to12 \\
\hline Water Absorption (\%) & 0.99 & 2.15 \\
\hline Specific Gravity & 2.65 & 2.53 \\
\hline $\begin{array}{l}\text { Bulk Density (Loose) } \\
\left(\mathrm{kg} / \mathrm{m}^{3}\right)\end{array}$ & 1289 & 1171 \\
\hline $\begin{array}{l}\text { Bulk Density (Rodded) } \\
\left(\mathrm{kg} / \mathrm{m}^{3}\right)\end{array}$ & 1445 & 1290 \\
\hline $\begin{array}{l}\text { Aggregate Impact Value } \\
(\%)\end{array}$ & 19 & 24 \\
\hline
\end{tabular}

\subsection{Concrete Compositions}

For this study, five different concrete compositions were prepared: one control composition having $100 \%$ $\mathrm{NA}$ and 4 compositions of RAC with $25 \%, 50 \%, 75 \%$ and $100 \%$ RA contents. All other ingredients of these concrete mixes were kept the same. The mix proportion of concrete prepared for this study is given in Table 3. As the water demand of RA is more than NA due to the mortar on the surface of aggregates and some aggregates particles comprising of mortar only, both NA and RA were used in saturated surface dry condition. The same water/cement ratio of 0.6 was used for all concrete mixes. Detail about the concrete compositions and the quantities of NA and RA is provided in Table 4. Regarding the nomenclature, $\mathrm{CC}$ 0 means concrete containing $0 \%$ RA (control mix). Further, RAC-25 means concrete containing 25\% RA and $75 \%$ NA (recycled aggregate concrete); and similarly others.

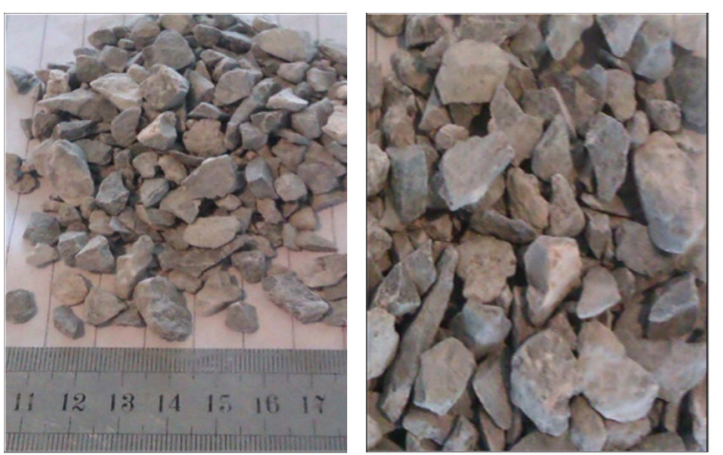

Fig.1: Natural Aggregates (NA)

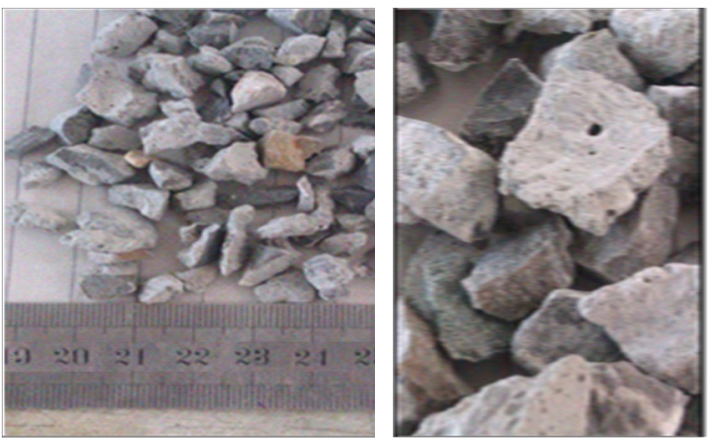

Fig.2: Recycled Aggregates (RA)

Table 3: Mix proportion of concrete (values in $\mathrm{kg} / \mathrm{m}^{3}$ )

\begin{tabular}{|c|c|c|c|}
\hline Cement & Sand & Aggregates & Water \\
\hline 216 & 432 & 864 & 130 \\
\hline
\end{tabular}

Table 4: Concrete mixes

\begin{tabular}{|c|c|c|c|}
\hline $\begin{array}{r}\text { Sr. } \\
\text { No. }\end{array}$ & Concrete mix & NA $(\%)$ & RA $(\%)$ \\
\hline 1 & CC-0 & 100 & 0 \\
\hline 2 & RAC-25 & 75 & 25 \\
\hline 3 & RAC-50 & 50 & 50 \\
\hline 4 & RAC-75 & 25 & 75 \\
\hline 5 & RAC-100 & 0 & 100 \\
\hline
\end{tabular}




\subsection{Test Specimens}

4 beams with a cross-section of $75 \mathrm{~mm} \times 150 \mathrm{~mm}$ and length of $1350 \mathrm{~mm}$ were cast for each concrete composition. Steel re-bars with a yield strength of 300 MPa were used as shear and flexural reinforcement. The reinforcement detail of the test specimen is shown in Fig.3. Flexure and shear reinforcement ratios were kept the same in all test specimens. One out of four beams of each concrete composition was tested under monotonic bending, while the remaining three beams were tested under reversed cyclic bending of three different amplitude levels of 4, 5 and $6 \mathrm{~mm}$. Test specimens were cast in steel molds and were compacted on a vibrating table. After casting, the specimen was covered with plastic sheets for 24 hours to avoid sudden evaporation of moisture. After demolding, test specimens were kept in a curing room for 28 days.

\subsection{Testing Setup}

Reverse cyclic tests were performed on the universal testing machine having a maximum bending load capacity of $500 \mathrm{kN}$. The schematic diagram and real picture of the testing setup are shown in Fig.4 and Fig.5, respectively.

\subsection{Reversed Cyclic Flexural Loading}

Displacement controlled tests at a loading rate of 10 $\mathrm{mm} / \mathrm{min}$ were performed and ten loading cycles with three different amplitude levels $(4,5$ and $6 \mathrm{~mm})$ were imposed. To decide about the amplitude levels for cyclic tests, a monotonic flexural loading test was performed on one beam of each class of concrete as mentioned above. In monotonic flexural loading test, test specimens were gradually loaded up to their maximum load-carrying capacity. The results of these tests performed on each type of RC beams in terms of load-deflection response are shown in Fig.6.

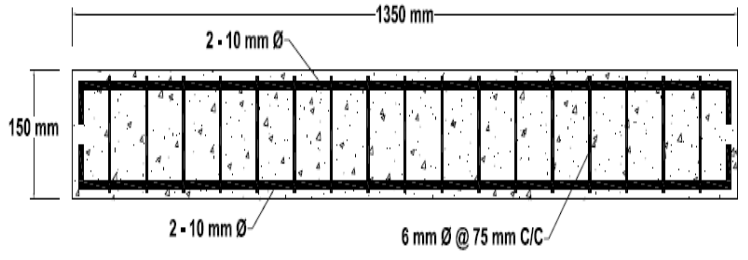

3(a): Longitudinal Section

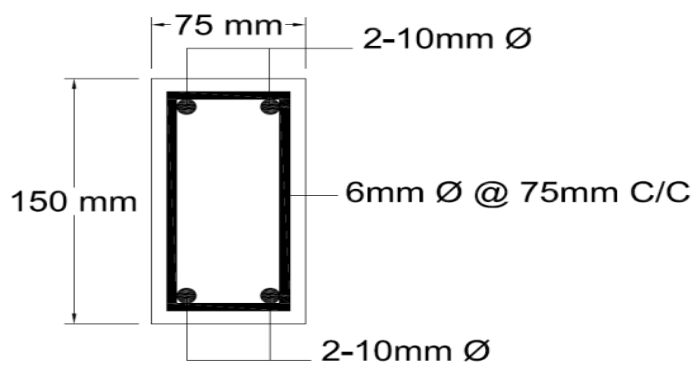

3(b) Cross Section

Fig.3: Reinforcement detail of test specimen

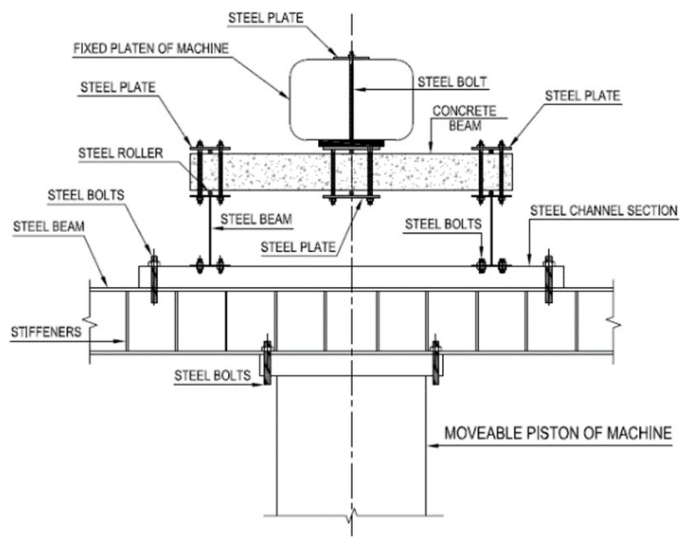

Fig.4: Schematic diagram of testing setup

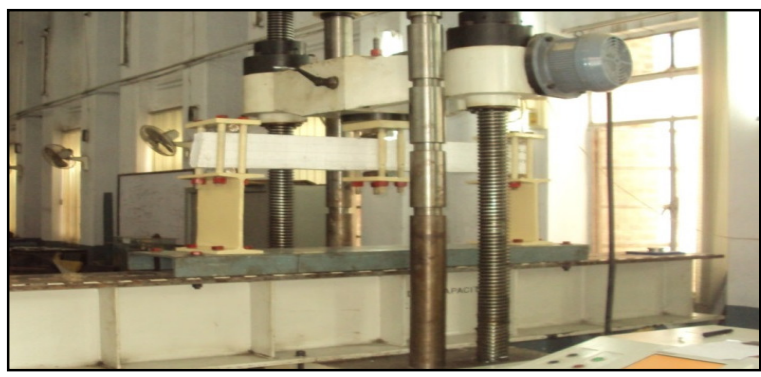

Fig. 5: Testing setup (Test in progress)

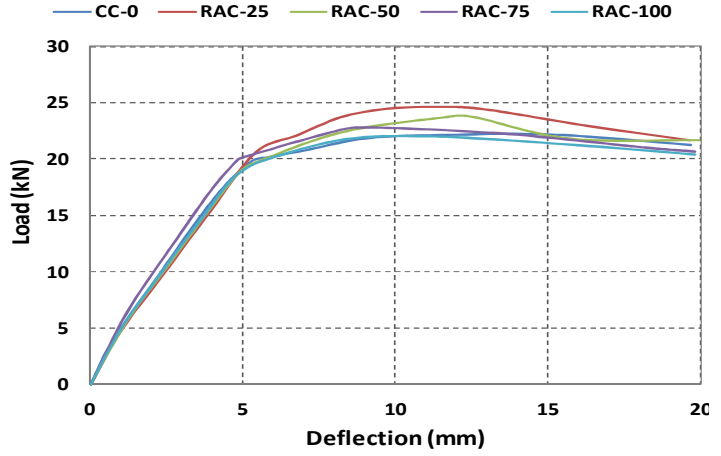

Fig.6: Load-deflection response of beams tested with monotonic bending 
In RC beams, different mechanisms that are responsible for a dissipation of energy include concrete cracking, yielding of steel bars, friction between steel and concrete and friction between cracked faces/surfaces. To study the effect of concrete cracking only on the energy dissipation capacity of RAC, a 4mm amplitude level was decided because at this amplitude level, concrete cracking was started in the beam without yielding of steel bars. To study the effect of steel bars yielding and concrete cracking on energy dissipation, a $5 \mathrm{~mm}$ amplitude level was decided because, at $5 \mathrm{~mm}$ deflection during monotonic flexure test, yielding of steel bars started and the loaddisplacement curve became non-linear as it is obvious in Fig.6. To investigate the overall and combined effect of all energy dissipating mechanisms, a $6 \mathrm{~mm}$ amplitude level was selected because up to $6 \mathrm{~mm}$ deflection during monotonic testing, significant cracking of RC beam occurred along with yielding of steel bars. Since the main focus of the study was to investigate the energy dissipation capacity of reinforced RAC; amplitude levels closer to deflection values obtained in monotonic testing where cracking of concrete was significant, were selected for reverse cyclic flexural testing.

\section{RESULTS AND DISCUSSION}

\subsection{Load Deflection Hysteresis Loops}

Experimental data in terms of load and deflection from the testing machine were automatically recorded using a data acquisition system. The data were in the form of hysteresis loops for 10 cycles of loading. These hysteresis loops of all 3 amplitude levels $(4 \mathrm{~mm}, 5 \mathrm{~mm}$ $\& 6 \mathrm{~mm}$ ) for the five compositions of concrete investigated in this study are shown in Fig.7 to Fig.9, where it can be noticed that the hysteresis loops of NAC and all classes of RAC are almost identical.
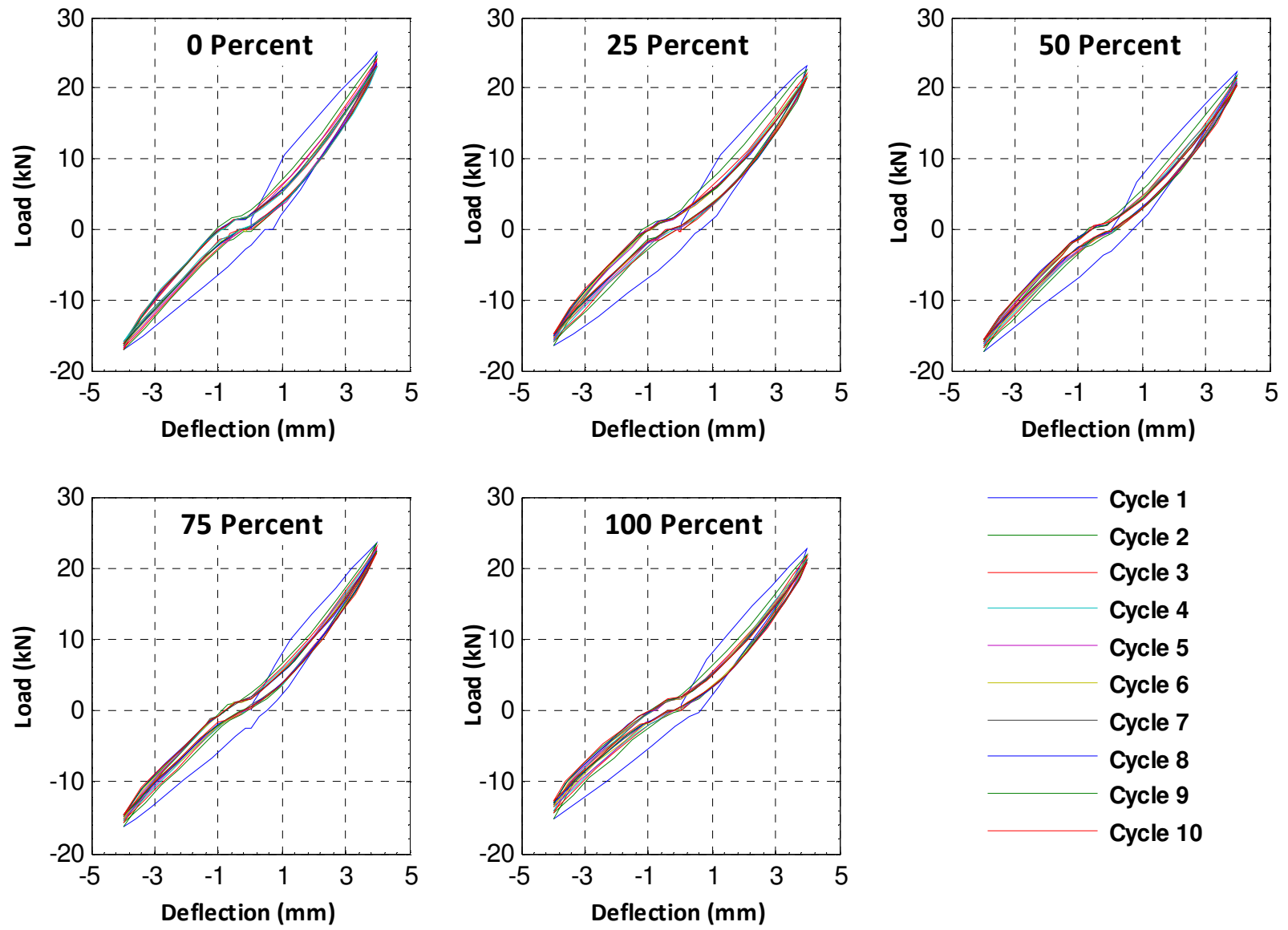

Fig.7: Hysteresis loops (loading cycles of $4 \mathrm{~mm}$ amplitude)3 

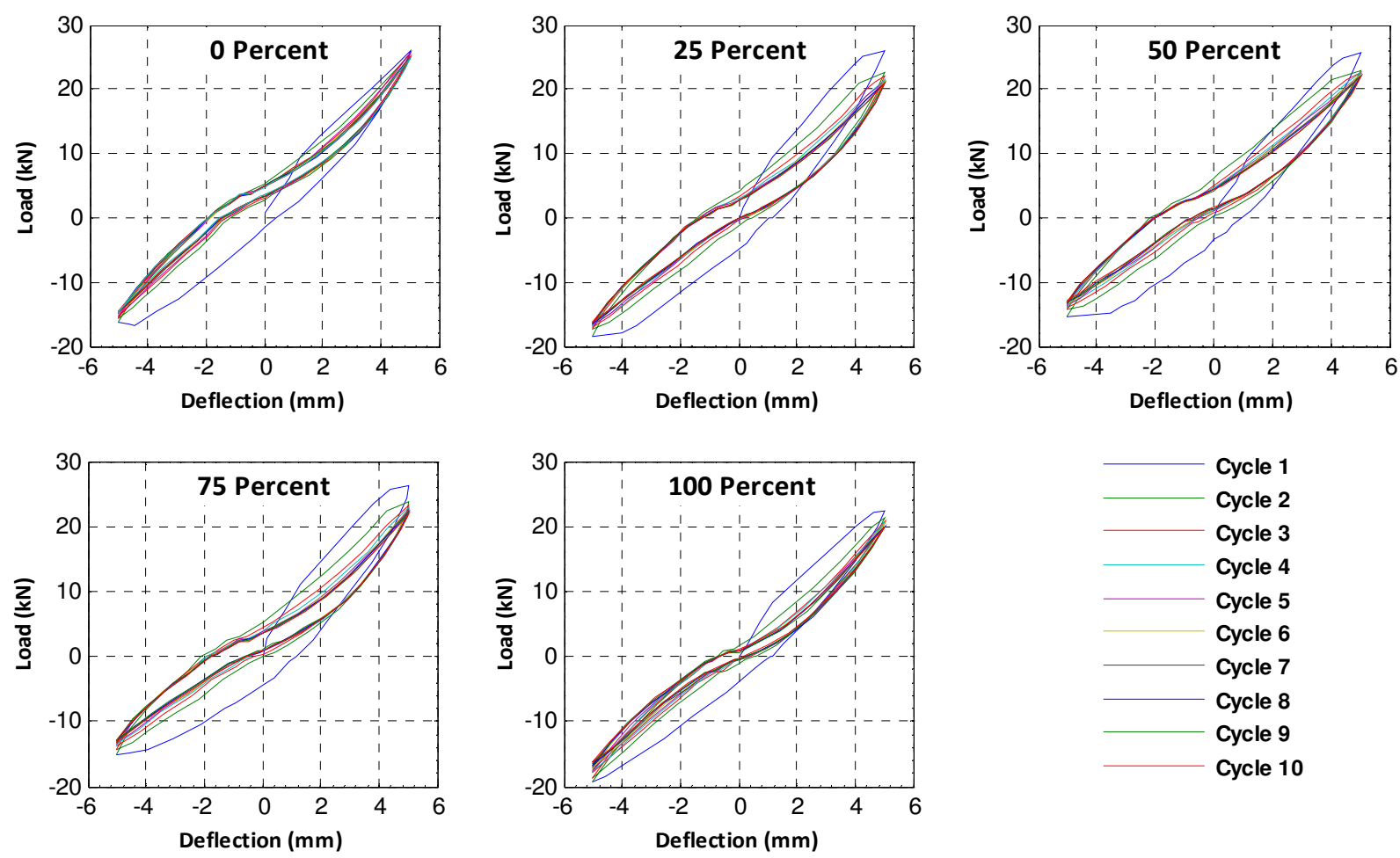

Cycle 1

Cycle 2

Cycle 3

Cycle 4

Cycle 5

Cycle 6

Cycle 7

Cycle 8

Cycle 9

Cycle 10

Fig.8: Hysteresis loops (loading cycles of $5 \mathrm{~mm}$ amplitude)
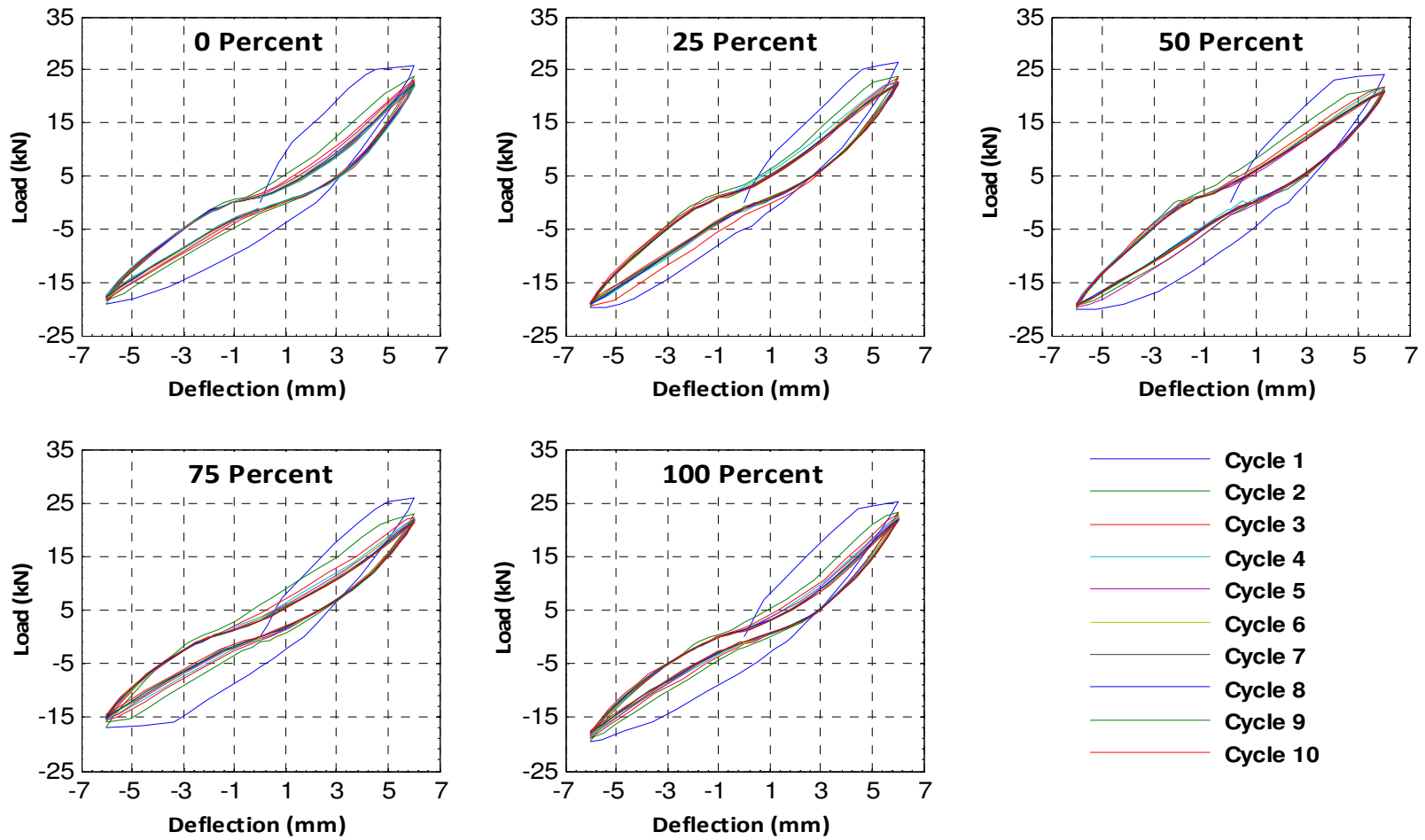

Cycle 1

Cycle 2

Cycle 3

Cycle 4

Cycle 5

Cycle 6

Cycle 7

Cycle 8

Cycle 9

Cycle 10

Fig.9: Hysteresis loops (loading cycles of $6 \mathrm{~mm}$ amplitude) 


\subsection{Cracking Pattern}

The cracking patterns of beams subjected to reverse cyclic flexural loading of amplitude $4 \mathrm{~mm}, 5 \mathrm{~mm}$ and $6 \mathrm{~mm}$ are shown in Fig.10, where it can be seen that similar to hysteresis loops there is no major difference in the cracking of $\mathrm{RC}$ beams containing $\mathrm{RA}$ at different percentage levels and 100\% NA (control RC beam) in terms of the number of cracks and crack spacing. Liu et al. [19] studied the seismic performance of RC columns made using RAC and made similar observations as in this study concerning cracking response of reinforced RAC; their research revealed that NAC and RAC columns exhibited similar failure process, and further demonstrated that behavior of hysteresis loops, energy dissipation capacity and ductility of RAC columns can meet the seismic requirements.
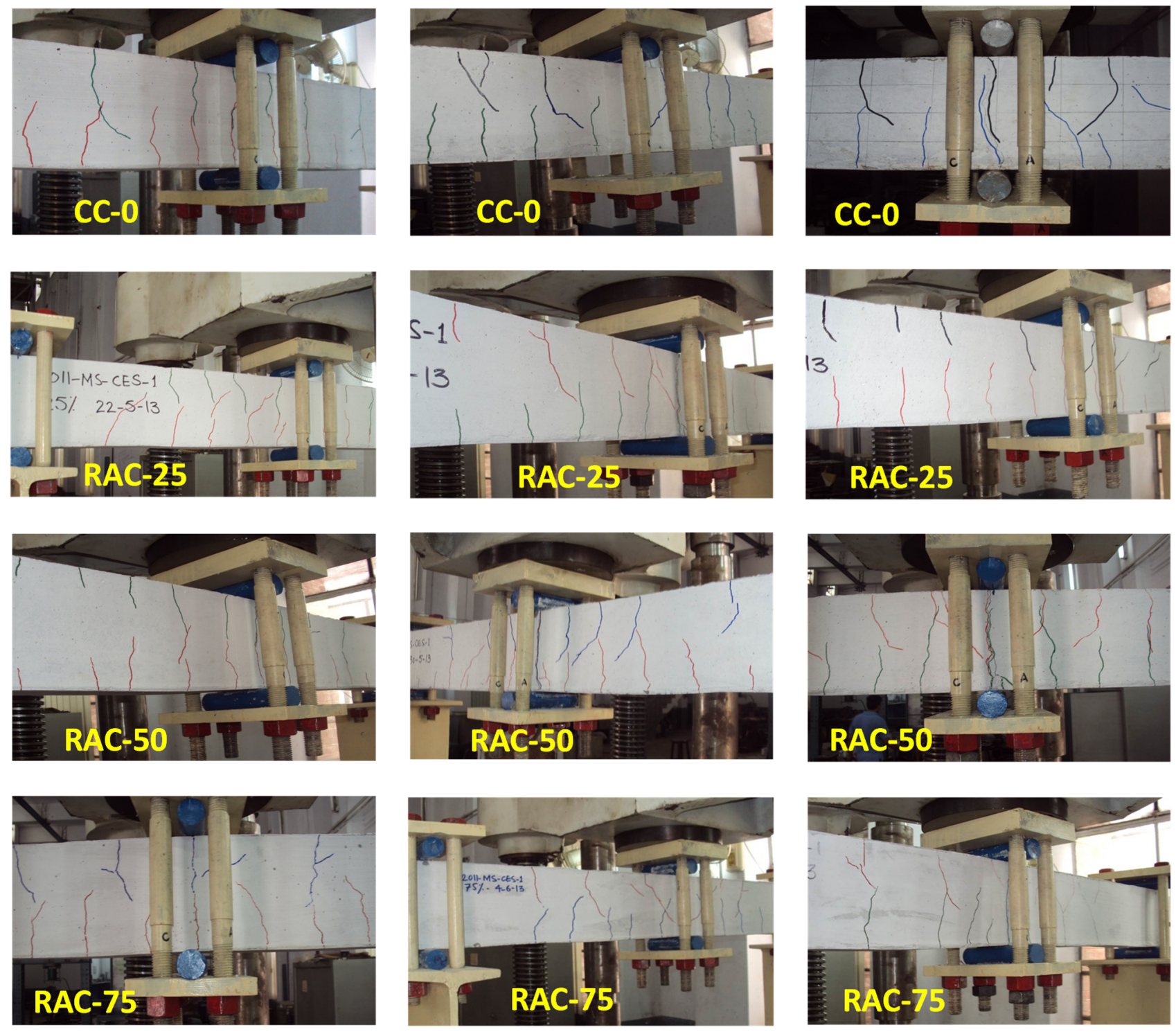


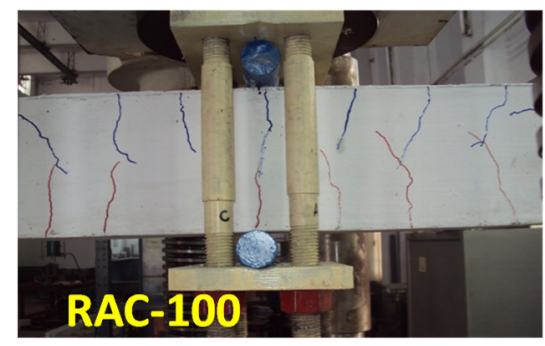

$4 \mathrm{~mm}$ amplitude

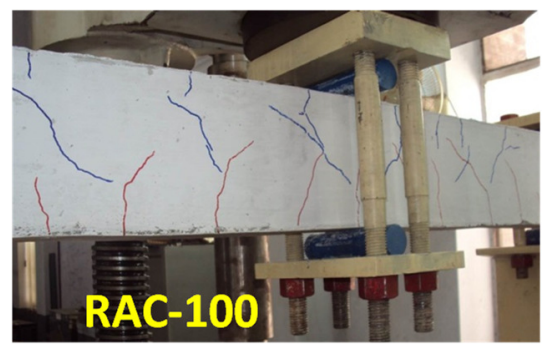

$5 \mathrm{~mm}$ amplitude

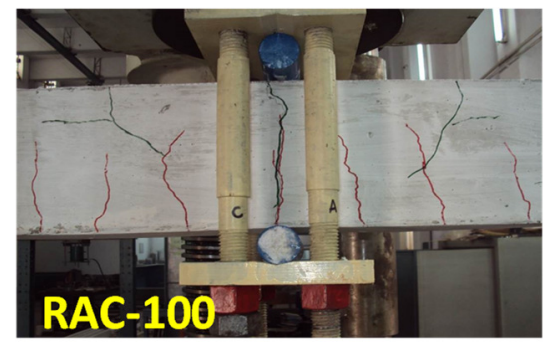

$6 \mathrm{~mm}$ amplitude

Fig. 10: Cracking patterns

\subsection{Energy Dissipation}

The energy dissipated during each loading cycle is represented by the area enclosed by the hysteresis loop for that particular cycle. The energy dissipated by each beam was computed and results have been presented and discussed here. Initially, the discussion focuses on energy dissipated in the first two cycles. Later on, cumulative dissipated energy (total energy dissipated in ten cycles) is discussed. The reason behind comparing results for the first two cycles separately lies in the fact that maximum energy was observed to be dissipated in the first two cycles because most of the cracks in each beam developed in the first two cycles. In the subsequent cycles, only the existing cracks opened and closed without the development of new cracks. During testing, it was observed that after about two cycles of loading, the crack at the center propagated in full depth of the beam while in subsequent cycles, only opening and closing of this crack occurred without a significant increase in dissipated energy from that of the previous cycle.

\subsubsection{Energy dissipation in first two cycles}

The values of energy dissipated in the first two cycles of loading for the three amplitude levels are shown in Fig.11 to Fig.13. It is clear in Fig.11 that for $4 \mathrm{~mm}$ amplitude level, RC beams made using control concrete (CC-0) and RAC containing 25\% RA exhibited a similar value of energy dissipation. However, beyond $25 \%$ replacement of NA with RA in the concrete mix, energy dissipation capacity was decreased and RC beams constructed using RAC-50, RAC-75 and RAC-100 attained a similar value of dissipated energy which was $19.3 \%$ less than that of control beam (CC-0). Since at this level of displacement amplitude (i.e., $4 \mathrm{~mm}$ ) the energy dissipation was mainly due to internal micro-cracking of concrete matrix, higher value of energy dissipation capacity with CC-0 and RAC- 25 beams was mainly attributed to their strong matrix compared to other RC beams (RAC-50, RAC-75 \& RAC-100) where presence of RA beyond $25 \%$ replacement level made the concrete matrix weaker resulting in lesser energy demand to develop cracking. This indicated that replacement of $25 \%$ NA with untreated RA with attached weaker and porous hardened cement paste did not affect the characteristics of the concrete matrix in $\mathrm{RC}$ beams and resulted in a similar value of energy dissipation capacity at $4 \mathrm{~mm}$ displacement amplitude as that of control beam. Further, in the first two loading cycles of $4 \mathrm{~mm}$ displacement amplitude, cracking in RC beams constructed using RAC-50, RAC-75 \& RAC-100 mixes were similar which resulted in almost the same energy dissipation capacity. However, at a greater amplitude of imposed displacement, damage/cracking of RA in concrete matrix significantly influenced the energy dissipation capacity of RC beams.

For $5 \mathrm{~mm}$ amplitude, RC beam constructed using RAC containing RA contents up to $75 \%$ performed better compared to the control beam (CC-0) in terms of energy dissipation capacity. This was mainly attributed to more diffused damage/cracking inside the concrete matrix in the presence of RA. As a result of steel bar yielding, more cracking in the RAC matrix around the steel bar due to axial deformation could also be another factor that caused an increase in energy dissipation capacity. However, the RC beam constructed using RAC containing 100\% RA exhibited dissipated energy value almost similar to 
that of the control beam (CC-0). This could be due to localized damage/cracking inside highly weak matrix due to $100 \%$ RA resulting in only widening and propagation of few initially developed cracks without development of new cracks. Compared to the control beam, the maximum increase of $52.2 \%$ in energy dissipation capacity was attained by the RC beam made using the RAC-50 mix. RC beams constructed using RAC-25 and RAC-75 exhibited energy dissipation capacity in the first two cycles of loading of $5 \mathrm{~mm}$ amplitude $45.5 \%$ and $39.7 \%$ more, respectively than the control beam $(\mathrm{CC}-0)$.

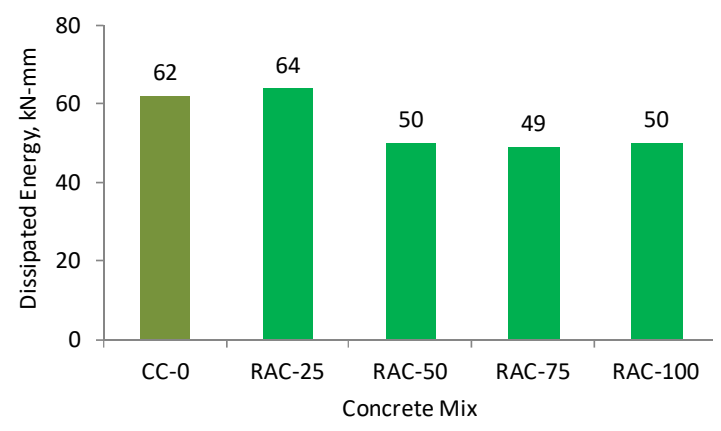

Fig.11: Dissipated energy in the first two cycles of $4 \mathrm{~mm}$ amplitude

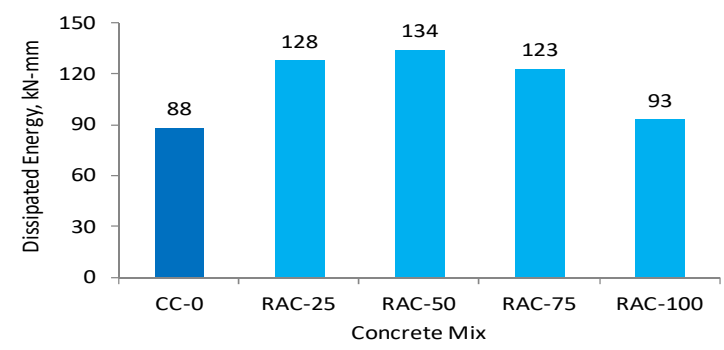

Fig.12: Dissipated energy in the first two cycles of $35 \mathrm{~mm}$ amplitude

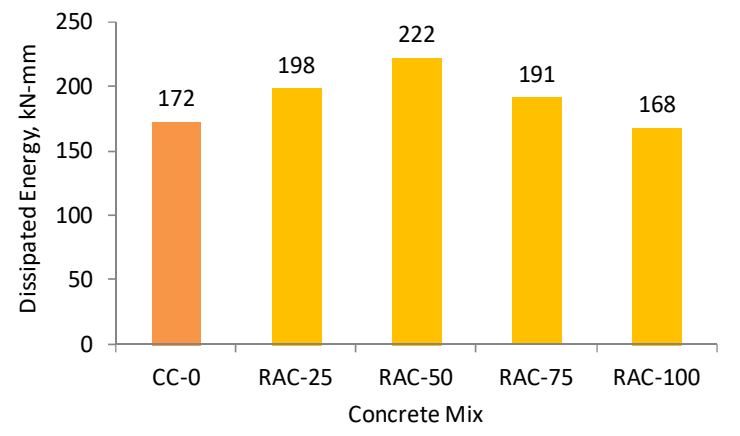

Fig.13: Dissipated energy in the first two cycles of $6 \mathrm{~mm}$ amplitude

An increase in amplitude value from 5 to $6 \mathrm{~mm}$ resulted in significant improvement in the energy dissipation capacity of all classes of RC beams in the first two loading cycles due to the development of new cracks, propagation of existing cracks and yielding of steel bars. Compared to energy dissipation capacity at $5 \mathrm{~mm}$ amplitude, RC beams constructed using CC-0, RAC25, RAC-50, RAC-75, and RAC-100 mixes showed $95.4 \%, 54.6 \%, 65.7 \%, 55.3 \%$, and $80.6 \%$ higher energy dissipation capacity, respectively at $6 \mathrm{~mm}$ amplitude. For comparison among different classes of concrete, a trend similar to that observed at $5 \mathrm{~mm}$ amplitude was noticed; maximum energy was dissipated by RC beam containing $50 \%$ RA which was $29 \%$ more than that of the control beam (CC-0). RC beams constructed using RAC-25 and RAC-75 exhibited energy dissipation capacity in the first two cycles of loading of $6 \mathrm{~mm}$ amplitude $15.1 \%$ and $11.1 \%$ more, respectively than control beam (CC-0). The minimum value of energy dissipation was attained by RC beam constructed using RAC-100 mix and the value was $2.3 \%$ less than that of the control beam.

\subsubsection{Cumulative Dissipated Energy}

Values of cumulative Dissipated Energy (DE) in 10 cycles of loading of 4,5 and $6 \mathrm{~mm}$ amplitude for each $\mathrm{RC}$ beams are presented in Fig. 14 to Fig.16, which showed almost the same trends as observed for values of dissipation energy in the first two cycles. Cumulative DE values presented in Fig.14 for $4 \mathrm{~mm}$ deflection amplitude revealed that $\mathrm{RC}$ beams constructed using control mix (CC-0) and RAC containing $25 \%$ RA exhibited an almost similar value of cumulative DE. However, increasing RA contents in concrete mix beyond $25 \%$ caused a reduction in cumulative DE. RC beams made using concrete mix RAC-50, RAC-75 and RAC-100 attained an almost similar value of cumulative $\mathrm{DE}$ which was found to be $20 \%$ less than that of control RC beam made using concrete mix CC-0. For $5 \mathrm{~mm}$ amplitude, RC beams constructed using RAC containing RA contents up to $75 \%$ attained a higher value of cumulative $\mathrm{DE}$ in comparison of control the RC beam (CC-0). However, $\mathrm{RC}$ beam constructed using RAC containing $100 \% \mathrm{RA}$ exhibited cumulative $\mathrm{DE}$ value almost similar to that of the control beam (CC-0). Compared to control RC beam, the maximum increase of $82.3 \%$ in cumulative DE was attained by the RC beam made using the RAC-

Mehran University Research Journal of Engineering and Technology, Vol. 40, No. 1, January 2021 [p-ISSN: 0254-7821, e-ISSN: 2413-7219] 
50 mix. RC beams constructed using RAC-25 and RAC-75 exhibited cumulative energy dissipation capacity $73.3 \%$ and $62.9 \%$ more, respectively than control RC beam (CC-0). Similar to energy dissipation capacity in the first two cycles, the increase in amplitude value from 5 to $6 \mathrm{~mm}$ resulted in significant improvement in cumulative $\mathrm{DE}$ for all classes of RC beams. Compared to values at $5 \mathrm{~mm}$ amplitude, RC beams constructed using CC-0, RAC-25, RAC-50, RAC-75, and RAC-100 mixes showed 2.26, 1.62, $1.84,1.62$ and 1.8 times higher cumulative $\mathrm{DE}$ capacity, respectively at $6 \mathrm{~mm}$ amplitude. For comparison among different classes of concrete, a trend similar to that observed at $5 \mathrm{~mm}$ amplitude was observed; maximum cumulative DE was attained by RC beam containing 50\% RA which was $48.9 \%$ more than that of the control beam (CC-0). RC beams constructed using RAC-25 and RAC-75 exhibited cumulative DE capacity at $6 \mathrm{~mm}$ amplitude $28.8 \%$ and $16.8 \%$ more, respectively than control beam (CC-0). The minimum value of cumulative $\mathrm{DE}$ was exhibited by the RC beam constructed using RAC-100 mix and the value was $11.6 \%$ less than that of the control beam.

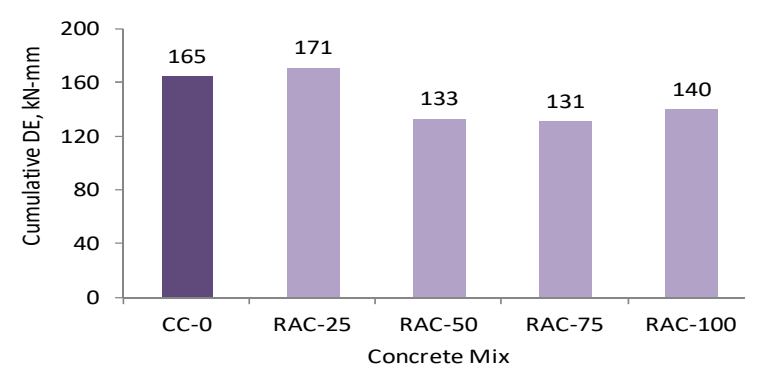

Fig.14: Cumulative dissipated energy in ten cycles of $4 \mathrm{~mm}$ amplitude

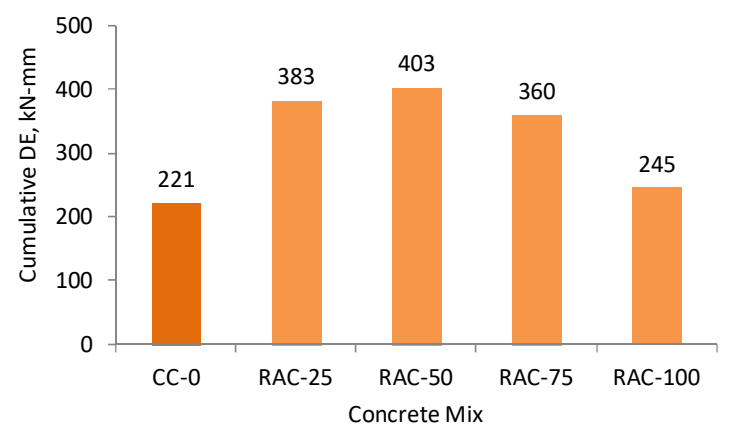

Fig.15: Cumulative dissipated energy in ten cycles of $5 \mathrm{~mm}$ amplitude

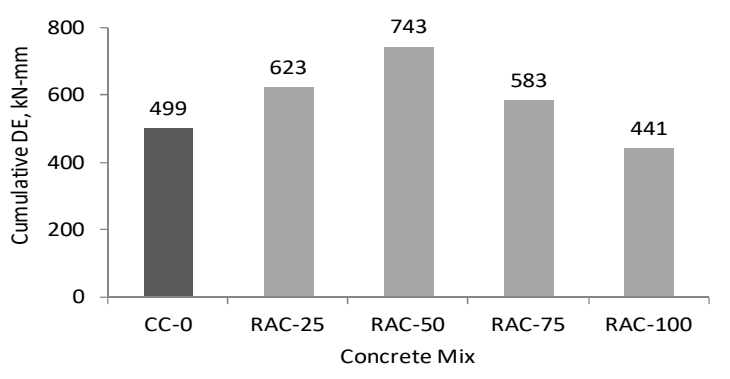

Fig.16: Cumulative dissipated energy in ten cycles of $6 \mathrm{~mm}$ amplitude

\section{CONCLUSIONS}

This study experimentally investigated the energy dissipation capacity of RC beams constructed using RAC concrete mix with varying percentage of recycled aggregates from $25 \%$ to $100 \%$. The beams were subjected to 10 cycles of reverse cyclic flexural loading of displacement amplitude of 4,5 and $6 \mathrm{~mm}$. Based on the results obtained and discussed above related to energy dissipation capacity and overall cracking behavior of test specimens, the following conclusions may be drawn:

1. No major difference in cracking behavior in terms of the number of cracks and their spacing was observed in RC beams constructed using NAC and RAC containing RA up to $100 \%$.

2. For all classes of RAC and NAC, a significant percentage of total energy was dissipated in the first two cycles of loading and this was true for three different imposed displacement amplitudes $(4,5$ and $6 \mathrm{~mm})$ investigated in this study.

3. Replacement of NA with RA up to $75 \%$ in reinforced concrete improved energy dissipation capacity, however, $100 \%$ replacement of NA with RA resulted in the energy dissipation capacity of $\mathrm{RC}$ beams almost similar to that of control RC beam.

4. For $4 \mathrm{~mm}$ displacement amplitude where concrete cracking mainly caused energy dissipation, optimum replacement level of NA with RA was found to be $25 \%$; RC beams constructed using RAC-25 mix exhibited almost same value of dissipation energy in the first two loading cycles and cumulative dissipated energy in 10 cycles as that of control RC beam constructed using $100 \%$ NA. 
5. For $5 \mathrm{~mm}$ and $6 \mathrm{~mm}$ displacement amplitudes where concrete cracking and steel yielding mainly caused energy dissipation, optimum replacement level of NA with RA was found to be $50 \%$; RC beams constructed using RAC-50 mix exhibited energy dissipation capacity in first two loading cycles and cumulative dissipated energy in 10 cycles $52.3 \%$ and $82.3 \%$ higher, respectively compared to control beam at $5 \mathrm{~mm}$ displacement amplitude while for $6 \mathrm{~mm}$ displacement amplitude, it was $29.1 \%$ and $48.9 \%$ higher, respectively when compared to control RC beam.

Hence, it is feasible to use recycled aggregates concrete in RC structures to get enhanced energy dissipation capacity which is important for structures in earthquake-prone areas. Further, the use of recycled aggregates will reduce the quantity of waste concrete and also contribute to conserving the natural resources of aggregates in Pakistan. In continuation of this study, future research will focus on studying the flexural behavior of fiber-reinforced recycled aggregate RC beams subjected to reversed cyclic bending. The addition of fibers is expected to further increase the energy dissipation of reinforced recycled aggregate concrete as fibers will act as another energy dissipaters in concrete.

\section{ACKNOWLEDGMENT}

Financial support provided by the University of Engineering and Technology, Lahore for carrying this study out is highly acknowledged and appreciated by the authors.

\section{REFERENCES}

[1]. Sami W. T., Akmal S. A., "Influence of recycled concrete aggregates on strength properties of concrete", Construction and Building Materials, Vol. 23, pp. 1163-1167, 2009.

[2]. Riaz M. R., Hameed R., Ilyas M., Akram A., Siddiqi Z. A., "Mechanical characterization of recycled aggregate concrete", Pakistan Journal of Engineering and Applied Sciences, Vol. 16, pp. 25-32, 2015.
[3]. Butler L., West J.S., Tighe S.L., "Effect of recycled concrete coarse aggregate from multiple sources on the hardened properties of concrete with equivalent compressive strength", Construction and Building Materials, Vol. 47, pp. 1292-1301, 2013.

[4]. Padmini A.K., Ramamurthy K., Mathews M.S., "Influence of parent concrete on the properties of recycled aggregate concrete", Construction and Building Materials, Vol. 23, pp. 829-836, 2009.

[5]. Amnon K., "Properties of concrete made with recycled aggregate from partially hydrated old concrete", Cement and Concrete Research, Vol. 33, pp. 703-711, 2003.

[6]. Liu, Q., Xiao, J., and Sun, Z., "Experimental study on the failure mechanism of recycled concrete", Cement and Concrete Research, Vol. 41, pp. 1050-1057, 2011.

[7]. Casuccio, M., Torrijos, M.C., Giaccio, G., and Zerbino, R., "Failure Mechanism of recycled aggregate concrete", Construction and Building Materials, Vol. 22, pp. 1500-1506, 2008.

[8]. Xiao, J., Li, W., Fan, Y., and Huang, X., “An overview of study on recycled aggregate concrete in China (1996-2011)", Construction and Building Materials, Vol. 31, pp. 364-383, 2012.

[9]. Kazemian F., Rooholamini H., Hassani A., "Mechanical and fracture properties of concrete containing treated and untreated recycled concrete aggregates", Construction and Building Materials, Vol. 209, pp. 690-700, 2019.

[10]. Guo H., Shi C., Guan X., Zhu J., Ding Y., Ling T-L., Zhang H., Wang Y., "Durability of recycled aggregate concrete - A review", Cement and Concrete Composites, Vol. 89, pp. 251-259, 2018.

[11]. Hu X., Lu Q., Xu Z., Zhang W., Cheng S., "Compressive stress-strain relation of recycled aggregate concrete under cyclic loading", Construction and Building Materials, Vol. 193, pp. 72-83, 2018.9 
[12]. Peng Q., Wang L., and Lu Q., "Influence of recycled coarse aggregate replacement percentage on fatigue performance of recycled aggregate concrete", Construction and Building Materials, Vol. 169, pp. 347-353, 2018.

[13]. Dong H., Song Y., Cao W., Sun W., Zhang J., "Flexural bond behavior of reinforced recycled aggregate concrete", Construction and Building Materials, Vol. 213, pp. 514-527, 2019.

[14]. Kim S-W., Lee B-S., Kim Y-S., Lee S-H., Kim K-H., "Structural Performance of Recycled Aggregate Concrete Confined by Spiral Reinforcement", Journal of Asian Architecture and Building Engineering, Vol. 17, pp. 541548, 2018.

[15]. Mohamad N., Khalifa H., Samad A.A.A., Mendis P., Goh W.I., "Structural performance of recycled aggregate in CSP slab subjected to flexure load", Construction and Building Materials, Vol. 115, pp. 669-680, 2016.

[16]. Xiao J., Li H., Yang Z., "Fatigue behavior of recycled aggregate concrete under compression and bending cyclic loading", Construction and Building Materials, Vol. 38, pp. 681-688, 2013.

[17]. Min Z., Sun W.M., Guo Z.G., "Experimental research on seismic behavior of recycled concrete frames", World Earthquake Engineering, Vol. 27, pp. 22-27, 2011.

[18]. Cao W.L., Yin H.P., Zhang J.W., Dong H.Y., Zhang Y.Q., "Seismic behavior experiment of recycled concrete frame structures", Journal of Beijing University of Technology, Vol. 37, pp. 191-198, 2011.

[19]. Liu C., Fan J., Bai G., Quan Z., Fu G., Zhu C., Fan Z., "Cyclic load tests and seismic performance of recycled aggregate concrete (RAC) columns", Construction and Building Materials, Vol. 195, pp. 682-694, 2019. 